\title{
KAJIAN BARU KRITIK HADITS JOSEPH SCHACT Studi Analisis “Teori Projecting Back”
}

\author{
Wely Dozan \\ UIN Sunan Kalijaga Yogyakarta
}

\begin{abstract}
Abstrack
Studies of the early-era hadiths have gone through so long and strict phases of the scholars. Hadith which are authentic sources after the Al-Qur'an makes the scholars devote their attention to maintaining the validity and continuity of the hadith. One form of appreciation for the Hadith is the number of books which contain the Prophet's hadith as a medium to save the Prophet's qaul. in the course of the study of the hadith including the form of writing and gathering it was not as easy as it had in mind. Because of this difficulty and various challenges, a handful of scholars from the west emerged to enter and try to find loopholes to weaken the authenticity of a hadith. Among them there are those who devote almost a portion of their lives to studying and deepening the hadith. But the results of their study of hadith are not all purely for the development of science, especially in the discipline of ulum al-hadis. One contribution of their thinking in the study of hadith is the emergence of several theories which aim to sue and undermine the theory of established Muslim scholars. In this paper, we will explore further the thoughts of orientalists and western scholars, especially Joseph Schact, who want to try to undermine the authenticity of hadith through a theory known as "Projecting Back" as well as objections made by Muslims to the theory.
\end{abstract}


Key words: Hadith, Teori Projcting Back Theory, Orientalis

\section{A. Pendahuluan}

Keyakinan umat Islam akan keontetikan sebuah hadis dan menjadikannya sebagai sumber ajaran Islam yang utama setelah alQur'an tidak diragukan lagi. Upaya-upaya pencarian keotentikan dan keabsahan sebuah hadis telah lama dilakukan sejak era sahabat hingga saat ini. Sejak dulu mentransmisikan segala bentuk perbuatan dan ucapan Nabi telah menjadi sebuah tradisi dalam kehidupan lintas generasi ke generasi. Sebagai figur, tentunya Nabi menjadi sumber keteladanan bagi ummatnya baik dalam kapasitasnya sebagai pemimpin, teladan, dan penyampain risalah Allah Swt.

Apresisasi yang tinggi terhadap hadis dalam sejarah awal telah ditunjukan oleh para sahabat sebagai puncak mata rantai periwayatan hadis. Hal ini terlihat banyaknya para sahabat yang menghadiri majelis-majelis yang dipimpin langsung oleh Nabi. Selain itu, para sahabat juga kerapkali berdiskusi dan saling bertukar informasi kepada sahabat lain perihal mengenai hadis yang mereka peroleh dari $\mathrm{Nabi}^{1}$. Setelah Nabi wafat, umat Islam tidak lagi dapat mendengar sabdasabda dan perbuatan beliau secara langsung. Tindak tanduk segala aspek yang berkaitan dengan Nabi hanya dapat digali dari para sahabat. Periwayatan sebagai jalan sampainya informasi yang berkaitan dengan Nabi terus dilakukan oleh generasi ke generasi selanjutnya, sehingga terus mengalami perkembangan serta melibatkan banyak pihak.

Dalam perjalanannya, bentuk periwayatan hadis memancing para ulama untuk lebih spesifik dan mengedapankan kehati-hatian dalam menerima sebuah hadis. Selain jarak wafatnya Rasulullah yang kian terlampau jauh dengan generasi-generasi sesudahnya dan banyaknya bentuk propaganda dan aliran-aliran dalam Islam mengakibatkan banyaknya hadis-hadis yang dipalsukan. Meskipun kemudian hadishadis palsu dapat diantasipasi oleh para ulama yang menyebabkan

1 Idri, "Otentitas Hadits Mutawatir dalam Teori Common Link G.H.A Juynboll Nomor 2, Maret 2013, hlm 250. 
hadis tidak semuanya dalam kondisi terbaik secara kualitas maupun kuantitas periwayatannya.

Banyaknya hadis dan bentuk periwayatan yang rumit menimbulkan sikap kritis dan skeptis dari para pengkaji hadis terutama dari kalangan non-muslim.

Para orientalis barat mencoba berusaha untuk mengkritisi hadits Nabi Muhammad Saw melalui berbagai ruang yang dikenal dengan istilah teori "projecting back" yang dimana toeri ini diperkenalkan oleh Joseph Schacht yang tidak percaya tentang keotentikan sebuah hadist. Sehingga dalam pemikiran Schact mengenai Hadits berusaha mencoba mengkritisi dengan melalui sandaran hadis (isnad) yang diteliti sebagai dasar untuk lebih mengkaji dalam lagi tentang kepalsuan hadits. Terutama hadits ulama fiqih klasik yang dijadikan sebagi bahan rujukan dalam mengkritisi hadits tersebut. Sehingga secara fundamental studi hadits di kalangan orientalis (Barat) berbeda dari kalangan umat islam tersebut. ${ }^{2}$

Gambaran sekilas dapat menjadi hal yang menarik dan perlu di kritisi, sehingga penulis mencoba menganalisa haasil pemikiran dari kalangan orientalis barat termasuk "Joseph Schacht" yang menginisiasi penemuan barunya sekaligus mengembangkan teori-teori yang berasal dari para pendahulunya. Hasil penelitiannya kemudian tertuang dalam karya The Origins of Muhammadan Jurisprudence (terbit 1950).

Schacht telah meyakani bahwa tidak ada satupun hadis yang benar-benar otentik terutama hadis-hadis yang berkaitan dengan hukum yang ia anggap sebagai kecendrungan periwayat untuk mengambil legitimasi dengan penyandaran riwayat pada generasi sebelumnya (projecting back). ${ }^{3}$

2 M.Nur khalis setiawan, Sahiron syamsuddin, Orientalisme Al-qur'an dan Hadits, (Center for the Study of Islam in North America, Western Europe and southeasth ASIA: Nawesea Press, 2007), hlm 177.

3 Abdul Mustaqim, "Teori Sistem Isnad Otentitas Hadis Menurut Perspektif M.M Azami” dalam Hamim Ilyas dan Suryadi (eds), Wacana Studi Hadis Kontemporer (Yogyakarta: Tiara Wacana, 2002), hlm 55-76.

Kajian Baru Kritik Hadits Joseph Schact.... 


\section{B. Pembahasan}

\section{Teori Projecting Back "Joseph Schacht"}

Teori projecting back merupakan teori yang timbul sebagai bentuk respon atas teori-teori yang telah dikembangkan oleh para sarjana muslim. Teori ini berangkat dari kebermulaan hukum islam di era awal. Anggapan ini muncul setelah pendalaman terhadap sejarah Islam yang mengklaim bahwa tidak ada Hadis-Hadis yang berkaitan dengan hukum Islam dan eksis pada masa al-Sya'bi (w. $110 \mathrm{H}$ ). Hal ini mengindikasikan bahwa hukum Islam baru dikenal semenjak masa pembentukan institusi peradilan dan menunjukan qadi' (hakim agama). Kira-kira pada akhir abad pertama Hijriah $( \pm 715-720 \mathrm{M})$. karena jumlah mereka makin bertambah banyak, maka akhirnya mereka berkembang dan membentuk kelompok ahli fikih klasik. Yang dalam pandangan Joseph Schacht, mereka inilah yang mengeluarkan fatwa-fatwa yang kemudian diklaim sebagai hadis Nabi. ${ }^{4}$

Pemikiran Hadits Joseph Schacht dalam teori "Projecting Back" sangat meragukan otentitas sanad hadits. ${ }^{5}$ Sanad (sandaran) atau

4 Idri, Hadis dan Orientalisme: Perspektif Ulama Hadi dan Orientalisme tentang Hadis Nabi, hlm 186.

5 Sanad menurut bahasa adalah sمعتلا: sesuatu yang dijadikan sandaran,

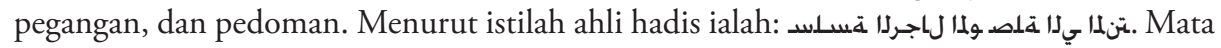
rantai para perawi hadis yang menghubungkan sampai kepada matan hadis. Dalam hal ini dikatakan bahwa sabda Nabi tersebut sampai kepada kita melalui periwayatan Al-Bukhari, Al-Bukhari melalui Ibnu Al-Mutsanna dari Abdul wahhab Ats-Tsaqafi dari Ayyub dari Abdul Qilabah dari Annas dari Nabi Saw. Hubungan mereka secara bermata rantai dan sandar menyandar dari si A ke B dan dari B ke Cdan seterusnya disebut sanad dan AlBukhari sebagai perawi atau mukharrij Artinya dialah yang meneyebutkan dalam kitab karyanya Al-jami' Ash-Shahih li Al-Bukhari. Demikian juga hadis kedua sampai kepada kita melalui periwayatan Al-Bukhari dari Abdullah bin Yusuf dari Malik dari Ibnu Syihab dari Muhammad dari Jubair dari Nabi Saw. Mereka itu disebut Sanad dan Al-Bukhari di sebut Mukharrij atau Perawi. Baca Abdul Majid Khon, Ulumul Hadits, hlm.97. Menurut Suryadilaga, Sanad dalam arti kebahasaan adalah sandaran atau sesuatu yang dijadikan sandaran. Dikatakan demikian karena bersandar kepadanya. Sedangkan menurut istilah, terdapat beberaparumusan pengertian. Al-Badr bin Jamaah dan at-Tibby, misalnya, menyatakan bahwa sanad adalah pemberitaan tentang munculnya suatu matan hadis. Yang lainya menyebutkan, sanad ialah silsilah atau rentetatan para perawi yang menukilkan hadis dari sumbernya yang pertama. Lihat suryadilaga, Ulumul Hadis, (Yogyakarta: Teras, 
Isnad (penyangga) di dalam hadits dapat dimaknai sebagai silsilah rangkaian dari para penyeleksi hadist, mulai dari sumber pertama sampai yang terakhir, mereka menganggap bahwa keaslian sebuah hadits disandarkan karena di anggap sebagai suatu yang fiktif (kreasi ulama abad ke-2 Hijriah atau tabi'in). Sanad yang pada awalnya lahir dalam pemakaian yang sederhana, dikembangkan dan diproyeksikan ke belakang sedemikian rupa sehingga terjadi pengadaan sanad pada generasi yang lebih tua. Hal ini dilakukan agar sesuatu itu mempunyai kekuatan yang lebih otoritatif. ${ }^{6}$

Dalam pengkajian Hadits Nabawi, Schacht lebih banyak menyoroti aspek sanad (Transmisi, silsilah keguruan) dari pada aspek matan (materi hadits) sementara kitab-kitab yang dipakai ajang penelitian adalah kitab al-Muwatta karya Imam Maliki, kitab alMuwatta karya Imam Muhammad al-Syaibani, serta kitab al-Umm dan al-Risalah karya Imam al-Syaf'i, kitab-kitab ini lebih layak disebut kitab fiqih dari pada kitab-kitab hadits kerena sebab kedua jenis kitab ini memiliki karakterisik yang bereda. Oleh karena itu, meneliti Hadits yang terdapat dalam kitab-kitab fiqih hasilnya tidak akan tepat penelitian hadits harus pada kitab-kitab hadits.

Lebih jauh lagi, menurut Joseph Schacht bahwa, hukum Islam (Fiqih Klasik) belum eksis pada masa al-Sya'bi (w. 110 H). Penegesan ini memberikan pengertian bahwa apabila ditemukan Hadis-hadis yang berkaitan dengan Hukum Islam, maka Hadis-hadis itu adalah buatan orang-orang yang hidup sesudah al-Sya'bi. Ia berpendapat bahwa Hukum Islam baru dikenal semenjak masa pengangkatan para qathi (hakim agama). Para Khalifah dahulu tidak pernah mengangkat para qadhi. Pengangkatan qadhi baru dilakukan pada masa "Dinasti Bani Umayyah". ${ }^{7}$ Kira-kira pada akhir abad pertama Hijriah (715-

2010), hlm 34 .

6 Nur Kholis Setiawan dkk, Orientalisme Al-Qur'an dan Hadits, (Center for the Study of Islam in North America, Western Europe and southeasth ASIA: Nawesea Press, 2007), hlm 186.

7 Dinasti Umayyah disebut juga Umayyah karena mengambil nama keturunan dari Umayah ibn Abdi Syam ibn Abdi Manaf. Ia adalah seorang terkemukadalam persurukan

Kajian Baru Kritik Hadits Joseph Schact.... 
$720 \mathrm{M})$ pengangkatan itu ditunjuk kepada orang-orang 'spesialis' yang berasal dari kalangan yang taat beragama. Karena orang-orang spesialis ini kian bertambah, maka akhirnya mereka berkembang menjadi kelompok Aliran Fiqih Klasik. Hal ini terjadi pada decadedecade pertama abad kedua Hijriah.

Adapun pemikiran Joseph Schacht munculnya aliran-aliran fiqih klasik membawa konsekuensi logis, yaitu munculnya kelompok oposisi yang terdiri dari Ahli-Ahli Hadits. Pemikiran dasar kelompok Ahli-Ahli Hadits ini adalah. bahwa Hadits-hadits yang berasal dari Nabi Saw harus dapat mengalahkan aturan-aturan yang dibuat oleh kelompok Aliran-aliran Fiqih. Oleh karena itu untuk mencapai tujuan ini, kelompok Ahli-ahli Hadits membuat penjelasan-penjelasan dan Hadits-hadits, seraya mengatakan bahwa hal itu pernah dikerjakan atau diucapkan oleh Nabi Saw mereka mengatakan bahwa, hal itu mereka terima secara lisan berdasarkan sanad yang bersambung dari para periwayatan Hadits dapat di percaya. ${ }^{8}$ Lebih jauh lagi, menurut Schacht, sikap aliran fiqih klasik ini semakin mendapatkan legistimasinya dengan adanya gerakan ahli al-hadits. Sekalipun semangat awal yang dibagun adalah tidak ingin hadits-hadits yang berasal dari Nabi Saw itu dikalahkan oleh aturan-aturan aliran fiqih namun untuk mencapai tujuan tersebut justru ahli hadits 'terjebak' pada sikap 'justifikasi' terhadap aturan-aturan aliran fiqih. Dari sinilah (Studinya terhadap revolusi sosial-historis konsep sunnah/hukum Islam).

Setelah terjadi rangkaian sanad-sanad hadits yang di ambil oleh

pada zaman Jahiliah, bergandeng dengan pamanya Hasyim ibn 'Abd Manaf. Umayyah dan Hasyim tersebut berpengaruh dalam proses-proses sosial politik pada zaman Jahiliyah, namun Umayyah lebih dominan. Hal ini disebabkan karena ia merupakan pengusaha yang kaya, dan memiliki banyak harta yang berlimpah. Padahal harta dan kekayaan menjadi faktor dominan untuk merebut hati dikalangan suku Quraisy. Dari nama umayyah tersebut, maka dinasti itu disebut dinasti Umayyah yang selama pemerintahanya telah terjadi pergantian sebanyak 14 khalifah.pada saat inilah pengangkatan di mulai pada masa hukum Islam. Baca Abdul Karim, Sejarah Pemikiran dan Peradaban Islam, (Yogyakarta: Bagaskara, Cet.VI Maret, 2014), hlm 113.

$8 \mathrm{Ibd}$. hlm 22. 
ulama fiqih klasik yang berbeda-beda, kemudian dapat mengantarkan Schacht pada kesimpulan controversialnya yang menantang pemahaman muslim tradisional bahwa hadits-hadits Nabi Saw sejauh berkaitan dengan persoalan-persoalan hukum agama, hampir-hampir tidak dapat dipertimbangkan sebagai hadits otentik, karena haditshadits tersebut merupakan kreasi ahli fiqih dan ahli hadits yang sengaja ditarik ke belakang agar memiliki kekuatan otoritatif. Di sini juga, rekonstruksi sanad itu terjadi. Dengan adanya proses penyandaran pendapat kepada masa lampau untuk mendapatkan landasan teori fiqih Islam. Otomatis akan terjadi pengadaan periwayatan yang selanjutnya. Inilah yang dimaksud oleh Schacht dalam "Projecting Back". Adapun orang yang melakukan usaha (rekontruksi sanad) disebut "Common Link".?

Melihat rangkaian sanad tersebut Schat dapat melakukan rekontruksi bahwa secara umum dapat dikatakan bahwa fiqih atau hukum Islam sudah dikenal semenjak Nabi Muhammad Saw. Sebab fiqih merupakan produk ijtihad pada mujtahid. Sementara para sahabat pada masa mereka, bahkan pada masa Nabi sudah melakukan ijtihad, karenanya sulit diterima tuduhan Schacht bahwa fiqih Islam baru muncul sesudah masa al-Sya'bi $(\mathrm{w} 110 \mathrm{H}$ ) sebagai produk keputusan-keputusan para qadhi yang diangkat pada masa Bani Umayyah. Sementara secara khusus orang yang banyak menangkisi teori dan tuduhan-tuduhan Schacht ini ialah Prof.Dr. M.M. Azami dalam bukunya Studies in Early Hadith Literature with a Critical Edition of some Early Texts. Beliau menangkis tuduhan-tuduhan Schacht dan menghancurkan argument-argumennya secara rinci dan

9 Teori Common link adalah istilah untuk seseorang periwayat hadits yang mendengar suatu hadits dari (jarang lebih dari) orang yang berwenang dan lalu ia menyiarkanya kepada sejumlah murid yang pada giliranya kebanyakan dari mereka meyiarkan lagi kepada dua atau lebih muridnya. Dengan kata lain, common link adalah periwayatan tertua yang disebut dalam berkas isnad yang meneruskan hadits kepada lebih dari satu murid. Dengan demikian, ketika berkas isnad hadits itu mulai menyebar untuk yang pertama kalinya maka di sanalah ditemukan common link-nya. Lihat G..H.A Juynbol, Teori Common Link (Melacak Akar Sejarah Hadits Nabi), (Yogyakarta: Lkis, 2007), hlm 3. 
ilmiah. ${ }^{10}$

\section{Analisis Metodologi Schacht Dalam Studinya Terhadap Sunnah}

Secara umum, para orientalis dalam menggugat keontetikan hadis dengan menggunakan tiga teori, yakni backward projection, argumentum e-silentio, dan common link. Tiga teori ini merupakan akar dari pemikiran Joseph Schacht yang dituangkan dalam bukunya The Origins of Muhammadan. Selanjutnya teori ini kemudian berkembang dan menjadi bahan kajian yang menarik bagi para pengkaji hadis baik dari kalangan outsider maupun insider. Selain itu teori-teori ini juga banyak mempengaruhi sarjana-sarjana barat yang muncul setelahnya. ${ }^{11}$

Joseph Schacht dalam menerapkan teorinya selalu merujuk pada hadis-hadis hukum, menurut Joseph Schacht, hadis hukum merupakan suatu bentuk inovasi yang muncul setelah beberapa pondasi Islam telah terbangun. Atau dengan kata lain kemunculan hadis hukum merupakan respon terhadap hukum-hukum yang sudah ada dalam masyarakat tradisional waktu itu yang lebih berpegang pada living tradition. Dalam bahasan ini teori backward projection atau projecting back kerapkali digunakan oleh Joseph Schacht untuk melacak penisbatan para ulama, kepada para sahabat sampai kepada Rasulullah saw.

Menurutnya (Tahammul al-'ilm), seperti "akhbarana" (kami diberi tahu oleh), "haddatsana" (kami diceritai oleh), dan sejenisnya. Istilah-istilah ini dipahami hanya membuktikan adanya penyebaran hadits secara lisan (oral transmission). Dalam hal ini penulis akan memberikan cotoh hadits secara garis beras yang biasanya menjadi sumber bahan kritikan kalangan orintalis tersebut. Contoh hadisnya dapat diperhatikan dibawah ini:

10 Ali Mustofa Yaqub, Kritik Hadits, hlm. 23

11 Wahyudin Darmalaksana, Hadis di Mata Orientalis : Telaah atas Pandangan Ignaz Goldziher dan Joseph Schacht (Bandung : Benang Merah Press, 2004) hlm 110 


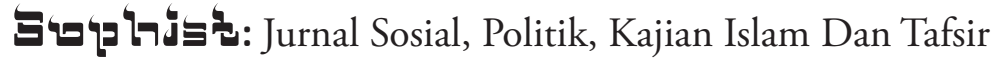

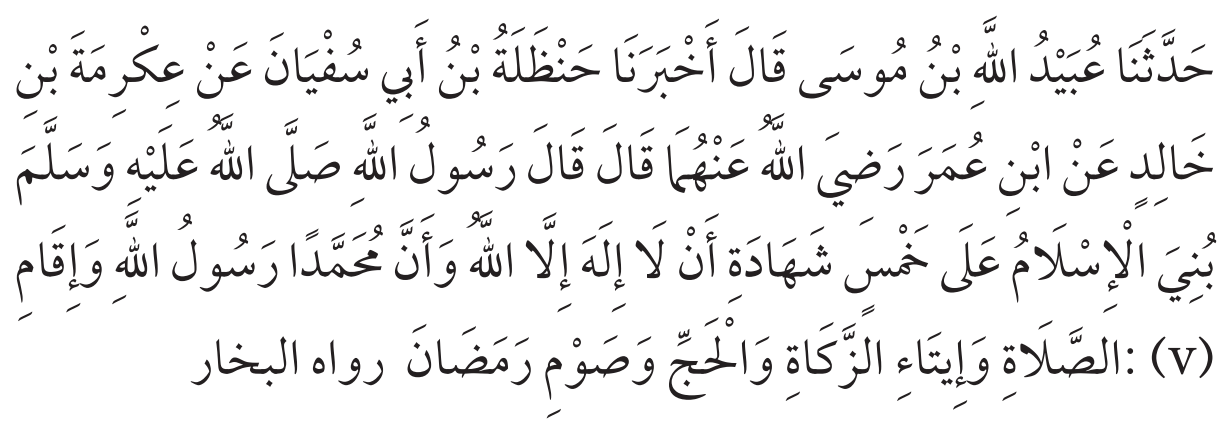

Artinya: Telah menceritakan kepada kami Abdullah bin Musa dia berkata, telah mengabarkan kepada kami Hanzhalah bin Abu Sufyan dari 'Ikrimah bin Khalid dari Ibnu Umar berkata: Rasulullah shallallahu 'alaihi wasallam bersabda: "Islam dibangun diatas lima (landasan); persaksian tidak ada ilah selain Allah dan sesungguhnya Muhammad utusan Allah, mendirikan shalat, menunaikan zakat, haji dan puasa Ramadlan". ${ }^{12}$

Lebih tegasnya, Joseph Schacht memandang bahwa sumber hadis Nabi adalah tabi'in yang kemudian disandarkan kepada para sahabat dan akhirnya disandarkan kepada Nabi Muhammad saw. Hal ini lebih kepada untuk melegitimasi pendapat dan agar mendapat mereka dapat pengakuan di tengah masyarakat. Orang-orang Kufah misalnya, seringkali mengaitkan teori-teori hukum mereka kepada Ibrahim an Nakha'i dan hal ini diikuti pula oleh orang-orang Madinah. Proses pengembalian pendapat kepada tokoh-tokoh di masa lampau ini kemudian berlanjut kepada tokoh-tokoh yang lebih klasik di kalangan sahabat, seperti Ibn Mas'ud, dan akhirnya kepada Nabi sendiri. Dengan demikian, menurutnya isnad hadis telah dipalsukan dan merupakan perkembangan pemikiran gerasi Islam awal. ${ }^{13}$ Joseph Schacht berkseimpulan bahwa rentetan periwayat yang terdapat dalam sanad hadis merupakan bentuk rekayasa dengan mengambil tokohtokoh yang popular di zamannya. ${ }^{14}$

Peran Nabi yang amat besar dan paling otoritatif dalam

12 Lihat selengkapnya, H.R. Bukhori Hadits, No.7.

13 Ali Masrur, Teori Common Link G.H.A Juynboll: Melacak Akar Kesejarahan Hadis Nabi (Cet. III;Yogyakarta: Lkis Yogyakarta, 20113), hlm 38-39.

14 Idri, Hadis dan Orientalisme:Perspektif Ulama Hadi dan Orientalisme tentang Hadis Nabi (Cet. I;Depok: Kencana, 2017), hlm 184.

100 Kajian Baru Kritik Hadits Joseph Schact.... 
membentuk sikap dan tingkah laku umat Islam. Karena alasan inilah Joseph schatcht beranggapan bahwa otoritas nabi yang amat besar akan sangat menggoda umat muslim untuk memanipulasi hadis demi kepentingan mereka. Pandangan skeptis seperti ini berimbas pada kesimpulan joseph terhadap hadist. Dalam kajian mendalam joseph terhadap hadis terutama hadis yang mengandung hukum, menyimpulkan bahwa hukum yang dikenal seperti sekarang itu masih belum ada di zaman Nabi Muhammad atau dalam dua abad pertama Islam. Hadis-hadis hukum yang dihimpun dalam kitab-kitab koleksi hadis menurutnya merupakan rekaan para ulama yang masih hidup. Sebagai contoh atas anggapan skeptis tersebut diutarakan pada kasus al-Hasan al-Basri (w. 110.728) ketika mengirim surat kepada Khalifah Bani Umayyah 'Abd l-Malik ibn Marean yang menginginkannya agar tidak iku ajaran Jabariyah dalam teologi sama tidak mengutip hadis sebagai bagian dari argumennya. Gambaran ini beimplikasi pada pemikiran joseph yang beranggapan bahwa hadis memang tidak ada di zaman tersebut.

Untuk lebih memperkuat kesimpulannya terhadap hadis, Joseph Schacht juga menganalisis hadis dengan salah satu tema yang dipakai dalam ilmu logika, yakni argumentum e-silentio. Teori ini dibangun atas asumsi bahwa cara terbaik untuk membuktikan bahwa sebuah hadis tidak ada pada masa tertentu adalah dengan cara menunjukkan bahwa hadis itu tidak dipergunakan sebagai argumentasi hukum dalam diskusi yang mengharuskan untuk merujuk kepadanya jika hadis itu memang ada. selain itu menurut Kamaruddin Amin teori ini merupakan kerangka dan proyeksi untuk mengungkap sejauh mana keeksisan sebuah riwayat dalam literature Hadis, apabila sebuah hadis tersebut tidak ditemukan dalam sebuah koleksi hadis, di mana eksistensinya pasti diharapkan, maka hadis tersebut tidak eksis pada hadis itu dibuat. ${ }^{15}$

Ini berarti, bahwa untuk memperkuat argument bahwa hadis

15 Kamaruddin Amin, Metode Kritik Hadis (Jakarta: Penerbit Hikmah, 2009), hal. 174 . 
itu merupakan suatu hal yang bersumber dari kalangan para tabi'in dengan merujuk pada historitas era sahabat dalam mengapresiasi sebuah hadis, sejauh mana hadis itu eksis ditengah para sahabat. Dengan upaya ini Joseph Schacht berupaya memahamkan sikap skeptis para sarjana muslim maupun barat bahwa kemunculan hadis itu berawal pada abad kedua dan ketiga hijriah dengan indikasi banyaknya hadis-hadis yang ditemukan tanpa isnad yang komplit, tetapi kemudian berkembangan menjadi isnad yang komplit.

Sebelum melakukan kritik terhadap hadis, Joseph Schacht menyodorkan tawaran sebagai konsep awal terhadap hadis. Tawaran tersebut berupa anggapan bahwa sunnah dalam konteks Islam pada mulanya memiliki sebuah konotasi politik ketimbang konotasi hukum; menunjukkan kebijaksanaan dan administrasi khalifah. Dalam hal ini adalah kisah yang menyangkut tentang kematian khalifah Utsman bin Affan pada tahun $35 \mathrm{H} / 655 \mathrm{M}$ yang dikenal dengan fitnah al-kubro. Pembunuhan tersebuh berawal dari tuduhan terhadap Utsman bin Affan yang telah menyalahi kebijakan para khalifah pendahulunya, secara implisit menyimpang dari al-Qur'an. Dalam hal ini muncullah konsep Sunnah Nabi, yang belum diidentifikasikan dengan sejumlah aturan-aturan positif, akan tetapi memberikan serangkaian mata rantai doctrinal antara Sunnah Abū Bakar dan Umar ibn al-Khattāb serta alQur'an. Bukti-bukti awal yang tentunya autentik untuk penggunaan istilah Sunnah Nabi adalah surah 'Abd Allah ibn 'Ibad, pemimpin Khawarij yang ditujujan kepada Khalifah Dinasti Umayyah, 'Abd alMalik, sekitar 76 H/695 M. istilah yang sama dengan sebuah konotasi teologis, yang disertai contoh teguran, terdapat dalam risalah Hasan al-Bashri yang ditujukan kepada Khalifah 'Abd al-Malik. Pengertian sunnah seperti ini diperkenalkan ke dalam teori hukum Islam yang diperkirakan berlangsung pada akhir abad pertama Hijriah oleh ulama-ulama Irak. ${ }^{16}$

16 Idri, Hadis dan Orientalisme: Perspektif Ulama Hadi dan Orientalisme tentang Hadis Nabi, hlm 185. 
Terkait dengan teori ini, Juynboll ${ }^{17}$ menerima dan menerapkannya dalam berbagai penelitainnya terhadap hadis, misalnya saja penelitiannya mengenai perubahan pendapat fuqaha yang kemudian bertransformasi menjadi hadis Nabi., sembagai sample dalam penerapan teori ini adalah seorang tabi' in yang bernama Sa'id bin Musayyab (w.94 H/ 713 M) yang dikenal sebagai pakar di bidang fikih. Menurutnya, banyak hadis yang pada masa-masa selanjutnya tampak dalam berbagai koleksi dengan isnad yang memuat namanya, sebenarnya bisa ditelusuri juga dalam sumber lainnya sebagai ungkapan dirinya sendiri yang tidak disandarkan pada otoritas yang lebih tua darinya. ${ }^{18}$

Sebagai pendukung utama teori Schacht, Juynboll lantas menawarkan skenario yang menurutnya lebih jelas untuk memahami teori ini. Dalam artikelnya yang berjudul "Some Notes of Islam First Fuqaha Distilled from Early Hadits Literature" (1992), dia memberikan tahapan sebagai penyempurna dari teori Projecting back: Pertama, pendapat (aqwal) yang muncul dari fuqaha' tertentu. Kedua, pendapat ini kemudian didukung oleh isnad mursal (terputus pada

17 Gautier H.A Juynboll lahir pada tahun 1935 di Leiden, salah satu pusat kajian orientalis terkemuka di Belanda. Ketertarikan Juyboll terhadap hadis telah ditunjukkan sejak jenjang akademik S1, ketika ia bergabung untuk mengedit sebagian dari kamus hadis Concordance et Indices de la Tradition Musulmanne dari pertengahan huruf ghayn hingga akhir. Juynboll menyelesaikan pendidikan doktoralnya pada Fakultas Sastra Universitas Negeri Laiden Belanda pada tahun 1969 setelah merampungkan penelitian tentang pemikiran para teolog Mesir dalam kurung waktu 1890-1960 terhadap hadis. Peletian Juynboll dilakukan selama dua tahun di Mesir dan tahun 1965 atas biasya netherland Organization for The Advancement of Pure Research (ZWO) dan diterbitkan oleh penertbit kajian Islam terkemuka di Belanda, E.J Brill pada tahun 1969. Minat terbesar Juynboll adalah studi hadis yang telah dilakukannya lebih dari puluh lima tahun. Jika kajian awalnya terkonsentrasi pada kajian hadis modern sebagaimana tercermin dalam proyek desertasi serta artikel berikutnya yang membahas tentang hadis oleh Pemerintahan Mesir untuk melakukan kampanye tentang penggunaan hadis oleh Pemerintah Mesir untuk melakukan kampanye

18 Beberapa diktum hokum Sa’id yang kemudian berubah menjadi hadis Nabi, yang berhasil dikumpulkan oleh Juynboll misanya, La talaqa qabla al-Nikah, diktum ini merupakan perkataan 'Ali, Abu Bakar bin Abd al-Rahman, 'Ubaidillah bin Abd Allah, Sa'id bin musayyad, dan lain sebagainya (al-Bukhari $b a$ talaq), tetapi kemudian menjadi hadis Nabi (Ibnu Majah bab talaq). Lihat, G.H.A. Juynboll, Muslim Tradition, hlm. 15 
tingkatan sahabat). Ketiga, pendapat ini lantas didukung oleh isnad yang mauquf(disandarkan pada sahabat). Keempat, barulah kemudian pendapat ini mendapatkan isnad marfü' (disandarkan pada Nabi).

Dari uraian dan penjelasan sikap josep terhadap hadis nabi melalui toeri projecting back secara umum dapat diringkas dalam enam poin ${ }^{19}$

a. System isnad dimulai pada abad kedua atau setidaknya pada akhir abad pertama Hijriah.

b. Isnad-isnad diletakkan secara sembarangan dan sewenangwenang oleh mereka yang ingin "memproyeksikan ke belakang" doktrin-doktrin mereka sampai kepada sumber-sumber klasik (projecting back).

c. Isnad-isnad secara bertahap "meningkat" oleh pemalsuan. Isnadisnad yang terdahulu tidak lengkap, tetapi semua kesenjangan dilengkapi pada masa koleksi-koleksi klasik.

d. Sumber-sumber tambahan diciptakan pada masa al-Syafi'I untuk menjawab-menjawab penolakan yang dibuat untuk Hadis-hadis yang dilacak ke belakang sampai kepada satu sumber

e. Isnad-isnad keluarga (family isnad) adalah palsu, demikian pula materi yang disampaikan di dalam isnad-isnad itu

f. Keberadaan common narrator dalam rantai periwayatan itu merupakan indukasi Hadis itu berasal dao perriwayat itu.

Sedangkan Muhammad Musatafa Azami mengintisarikan bahwa sentral Tesis Schacht bergantung pada penggunaan konsep sunah yang secara ringkas Schacht berpendapat bahwa:

a. Konsep awal sunnah adalah kebiasaan atau praktek yang disepakati secara umum, yang disebutnya sebagai "tradisi yang hidup"/living tradition"

19 Idri, Hadis dan Orientalisme: Perspektif Ulama Hadi dan Orientalisme tentang Hadis Nabi, hlm 190.

104 Kajian Baru Kritik Hadits Joseph Schact.... 
b. Konsep sunnah Nabi pada asal-usulnya relatif terlambat, dibuat oleh orang-orang Irak pada sekitar abad kedua Hijriah.

c. Penggunaan istilah "Sunnah Nabi" tidak berarti Sunnah yang sebenarnya berasal dari Nabi, tetapi hanya sekedar " tradisi yang hidup" dari mazhab yang ada diproyeksikan ke belakang hingga disandarkan ke lisan Nabi Muhammad

\section{Penutup}

Joseph Schacht dalam menerapkan teorinya selalu merujuk pada hadis-hadis hukum, menurut Joseph Schacht, hadis hukum merupakan suatu bentuk inovasi yang muncul setelah beberapa pondasi Islam telah terbangun. Atau dengan kata lain kemunculan hadis hukum merupakan respon terhadap hukum-hukum yang sudah ada dalam masyarakat tradisional waktu itu yang lebih berpegang pada living tradition. Dalam bahasan ini teori backward projection atau projecting back kerapkali digunakan oleh Joseph Schacht untuk melacak penisbatan para ulama, kepada para sahabat sampai kepada Rasulullah saw.

Sebelum melakukan kritik terhadap hadis, Joseph Schacht menyodorkan tawaran sebagai konsep awal terhadap hadis. Tawaran tersebut berupa anggapan bahwa sunnah dalam konteks Islam pada mulanya memiliki sebuah konotasi politik ketimbang konotasi hukum; menunjukkan kebijaksanaan dan administrasi khalifah. Dalam hal ini adalah kisah yang menyangkut tentang kematian khalifah Utsman bin Affan pada tahun $35 \mathrm{H} / 655 \mathrm{M}$ yang dikenal dengan fitnah al-kubro. Pembunuhan tersebuh berawal dari tuduhan terhadap Utsman bin Affan yang telah menyalahi kebijakan para khalifah pendahulunya, secara implisit menyimpang dari al-Qur'an. Dalam hal ini muncullah konsep Sunnah Nabi, yang belum diidentifikasikan dengan sejumlah aturan-aturan positif, akan tetapi memberikan serangkaian mata rantai doctrinal antara Sunnah Abu Bakar dan Umar ibn al-Khattab serta al-Qur'an. 


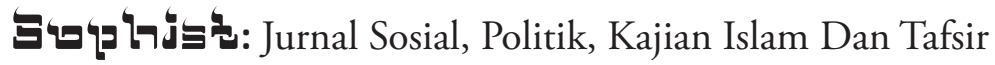

\section{DAFTAR PUSTAKA}

Amin, Kamaruddin. "Diskursus Hadis di Jerman" dalam www. Islamlib.com/ 13 Maret 2005/diakses 3 November 2018. , Metode Kritik Hadis,Jakarta: Penerbit Hikmah, 2009.

Darmalaksana, Wahyudin. Hadis di Mata Orientalis : Telaah atas Pandangan Ignaz Goldziher dan Joseph Schacht, Bandung : Benang Merah Press, 2004.

Hadi, Khoirul dalam Joseph Schacht's Contribution To The Study Of Islamic Law, Tesis, (Kanada: Institute of Islamic Studies McGill University, 1992.

Hafid, Erwin. dalam Kritik Hadis, Jakarta: Pustaka Firdaus, 1995.

Idri, Epistemologi Ilmu Pengetahuan, Ilmu Hadism dan Ilmu Hukum Islam, Jakarta: Kencana, 2015.

, Hadis dan Orientalisme: Perspektif Ulama Hadi dan Orientalisme tentang Hadis Nabi, Cet. I; Depok: Kencana, 2017.

. "Otentitas Hadits Mutawatir dalam Teori Common Link G.H.A Juynboll”, Nomor 2, maret 2013.

Ismail, M. Syuhudi Kaidah Kesahihan Sanda Hadis: Telaah Kritis dan Tinjauan dengan Pendekatan Ilmu Sejarah, Jakarta: Bulan Bintang, 1998.

Masrur, Ali Teori Common Link G.H.A Juynboll: Melacak Akar Kesejarahan Hadis Nabi, Cet.III; Yogyakarta: Lkis Yogyakarta, 20113.

Mustaqim, Abdul. "Teori Sistem Isnad Otentitas Hadis Menurut Perspektif M.M Azami” dalam Hamim Ilyas dan Suryadi (eds), Wacana Studi Hadis Kontemporer, Yogyakarta: Tiara Wacana, 2002.

106 Kajian Baru Kritik Hadits Joseph Schact.... 
M.Nur khalis setiawan, Sahiron syamsuddin, Orientalisme Al-qur'an dan Hadits, (Center for the Study of Islam in North America, Western Europe and southeasth ASIA: Nawesea Press, 2007.

Mahmudah. Nur, "Pemikiran G.H.A Juynboll Tentang Hadis."Jurnal Mutawtir. Vol 3. No.1.2013

Setiawan. Cahya Edi, Studi hadis: Analisis Pemikiran Pemikiran Schacht Dan A'zami, Jurnal: Vol. 4 No. 1 Juli 2018. 